nerves, like the nervus accessorius, the third, fourth, and sixth pairs, a great part of the facial,* and that undeniably, really should arise from the posterior columns, for according to their hypothesis, sersor nerves only should thence arise, and that such undeniable cases as those of Dr. Webster, Mr. Stanley, and Dr. Budd, show that, with the gradual destruction of the posterior columns of the spinal cord was lost the power of motion.

Cannot physiologists see that the recognising the anterior columns as sensor and the posterior as motor would at once conform to truth, reconcile all anomalies, and obviate every difficulty? This, founded upon anatomy, analogy, genesis, and pathology, I have taught for nearly forty years, at great cost, which I could bear only by accumulating debts that I may never repay, and consequently by embarrassing and distress ing myself for life; - which could I have foreseen, I should have preferred the lowest and humblest mechanic trade to the cultivation of science.

(To be continued.)

\section{ON THE APPLICATION OF VINEGAR IN THE TREATMENT OF ULCERS.}

By CHARLES HENRY BARBER, M.R.C.S.E., Colsterworth.

I AN well aware that vinegar has gained considerable notoriety both as an internal and external remedy. I beg to inform my professional brethren that I have found common vinegar (in chronic and extensive old ulcers of the leg) a most excellent detergent and antiseptic application; so much so (according to my views) as completely to supersede all the most noted greasy unguents that have been handed down for centuries from our forefathers.

I have found vinegar particularly adapted to those old extensive chronic ulcers in after life, where there is an extensive discharge, and also a disinclination in poor people to take much trouble in keeping the wounds clean and free from smell. I have frequently received the thanks of pauper patients for telling them to dress their wounds with common vinegar and nothing else. The manner in which I generally recommend the vinegar to be used is as follows-viz., the diseased leg (I say the leg, because it is upon the lower extremities we find the majority of the most troublesome ulcers) should be bathed every morning with warm or cold water, so as to make it quite clean; after which, the wound is to be bathed with common vinegar; then moisten a piece of lint or linen cloth, the size of the wound, with the vinegar, and apply it over the ulcer, and after this dressing apply a bandage in the usual way over the wound. A leg thus managed becomes free from that unpleasant smell which accompanies wounds from which there is a great discharge, and which are dressed with ointments: the granulations become healthy, and the patient does not experience any unpleasant sensation from the application.

Now, as to pyroligneous acid as an external application. There are some cutaneous ulcers and warty excrescences which frequently derive much benefit, and very often are cured by the employment of the concentrated pyroligneous acid. The parts affected should be painted over with a camel's hair pencil dipped in the acid, and afterwards covered with a dry lint every or every other morning.

Colsterworth, October 18, 1848

\section{Rebúctus.}

On the Infuenza, or Epidemic Catarrhal Fever of 1847-48. By Thomas Bevilu Peacock, M.D., Physician to the Royal Free Hospital, and to the City of London Hospital for Diseases of the Chest. London: Churchill. 1848. pp. 182. THe histories of epidemics are amongst the most valuable contributions to our science. They are the evidence of its progress from the days of hypothesis and prejudiced conceptions, to the truthful digests of our own Sydenham, whose reputation is

* Those cerebral nerves which are at once nerves of sensation and volition have of conrse two roots, one from the cerebrum and another from the cerebellum. This may be mnst easily observed in the seventh pair, or facial nerves, the origin of which has hitherto been mistaken by most, if not all, anatomists. They directly penetrate the medulla oblongata from its lower to its upper surface; or oppositely, and throughout this very considerable internal passage, each nerve consists of two perfectly distinct, silvery, and glistening cords, of which one joms the cerebellum, and the other runs onward to the cerebrum. This may be easily seen by any anatomist who chooses to look at the subject itself. well founded on the closeness of his observation, and on the historical accuracy with which he recorded what he saw. Unfortunately, our records, even since this example has been given us, are of unequal value. As in the political world, few men can undertake the task of writing history successfully, so in our world there are not many competent to perform a duty requiring equal, if not greater mental powers, that duty being to observe and chronicle the history of disease. The medical historian must be a man who knows how to observe facts, to estimate their value, and to apply them. He must therefore be as learned as he is practical-he must be of unwearied industry. Above all, he must be free from prejudice or bias, and, to secure confidence, his opinions must be given with sincerity and candour. He must indicate with equal force what is known, and what remains to be known. He must say much about the disease, little about himself. If a writer thus qualified can well arrange his views, and can express them clearly and concisely, his work must be valuable for the present and the future. The recent epidemic influenza has fortunately found in Dr. Peacock an historian possessed of the essential qualifications which we have thus sketched, and the result is the very excellent volume, the title of which heads this article, and which we propose to notice here. Under ordinary circumstances, the critic is rarely at a loss for some point which admits of doubt or question-some field on which the display of his acumen or his knowledge may be made-but here, whether owing to the peculiar nature of the subject, or, perhaps, rather to the circumstance that we have before us a truthful narration of positive facts, the critic's "occupation 's gone," and he must confine himself to an analysis of the fare placed before him, and to giving some extracts as examples of the author's style. The volume consists of seven chapters or divisions. The first gives a review of the commencement and progress of the disease in the metropolis. The three following contain descriptions of its three principal varieties, according to the author's view - viz., 1st. Simple Catarrhal Fever; 2ndly. Catarrhal Fever, with Pulmonary Complication; 3rdly. Catarrhal Fever, with Abdominal Complication. The fifth chapter is devoted to the consideration of the treatment of these several forms of disease. The sixth includes the author's views on the nature and causes of the epidemic; whilst the seventh gives the details of some twenty cases of the disease, which had been closely followed and observed.

Dr. Peacock's observations are founded principally on the cases amongst the in and out-door patients treated by him at the Royal Free Hospital. The use which he has thus made of his practice is most creditable to him, and leads us to remark that the institution is extremely fortunate in the possession of so indefatigable and accomplished a physician. Without referring at any length to the histories of preceding. epidemics, we learn that there are records from the thirteenth century of the visitations of influenza as an epidenic, about ten or a dozen times on an average in each century. In large towns, in general, little more than half the inhabitants escape its attack; and in London, during the last epidemic, the mortality was increased by 5000 deaths in six weeks. The disease is known by various denominations. It was first called influenza in Venice and Milan in 1741. It bears in France the uneuphonious name of Grippe. By the old English writers it was called Pose; in Irish, Fuacht, and Slaodan. In early Gaelic manuscripts a disease similarly characterized is named Creatan; it is, however, most generally recognised by its Italian designation, Influenza, or as Epidemic Catarrhal Fever.

The author, in his introductory chapter, fully discusses this part of the subject. He also describes the localities visited throughout the world by the disease, and the various dates at which it has made its appearance. The weather before and during the recent epidemic is described. Here the chief points of interest seem to have been the small amount of electricity 